\title{
Kamusal Alanların Evrilmesi
}

\author{
Fülay UYSAL BILGE ${ }^{1 *}$
}

Öz

Kamusal alanlar tarih boyunca kentlerin en önemli parçası olarak, gündelik yaşamın birlikte geçebileceği, paylaşım alanları olmuştur. Günümüzde ortaya çıkan küresel salgınla birlikte, kamusal açık alanların ve yeşil alanların önemi artmaktadır. Kentlerde, belirli mesafelerin korunarak ortak yaşamın geçtiği kamusal açık alanlardaki yeşil alanların düşünülmesi sağlıklı yaşam için önem taşımaktadır. Bu noktada, çalışmanın temel amacı, kamusal alan olgusunu kavramak, kentlerin gelişimiyle ortaya çıkan değişimini anlamak ve tartışmak, bu tartışma sonucu geleceğin kamusal açık alanlarının nasıl olması gerektiğine dair yeni veriler oluşturulmasıdır. Bu bağlamda, kentlerin gelişim süreçleri ele alınarak, kamusal alan ve kamusal yaşam olguları araştırılmakta, bu kavramlara yönelik tanımlar incelenmektedir. Yaklaşımlar değerlendirildikten sonra, kamusal alan kavramının kentsel mekânla olan ilişkisi, teorisyen ve mimarların tanımlarıyla ele alınmaktadır. Literatürden ortaya çıkan tanımlardan, kamusal alan kavramının kavramsal ve fiziksel genel tanımlaması yapılmaktadır. Bu tanım üzerinden, tarihsel süreçte kentlerin gelişmesiyle, kamusal alan kavramındaki değişimler ortaya çıkartılmaktadır. Kamusal alanın değişimi üzerine, hem yurtiçi hem de yurtdışı örneklerin değerlendirmeleri yapılmaktadır. Çalışmada vurgulanan kamusal alan olgusunun öneminin ve kamusal açık alanlara olan gereksinimin, salgınla birlikte daha da artacağı düşünülerek, gelecekte tasarlanacak kamusal açık alanlara yönelik öneriler ölçütler belirlenerek, çalışma tamamlanmaktadır.

Anahtar Kelimeler: Kamusal alan, Kentsel kamusal açık alan, Kamusal alandaki değişimler, Kamusal alanların evrilmesi

\section{Evolution of Public Spaces}

\begin{abstract}
\footnotetext{
${ }^{1}$ Atılım Üniversitesi Güzel Sanatlar, Tasarım ve Mimarlık Fakültesi, Mimarlık Bölümü, Ankara

* İlgili yazar/Corresponding author: fulay.uysal@atilim.edu.tr

Gönderim Tarihi / Received Date: 24.12.2020

Kabul Tarihi / Accepted Date: 31.03.2021
}

Public spaces are the shared spaces where Daily life can be spent together as the most important part of cities throughout history. The importance of public open spaces and green spaces have been increased due to the pandemic occurred today. Evaluation of green spaces in public open spaces in which common life is spent with social distance in cities is crucial. Therefore, the main purpose of this study is to grasp the phenomenon of public space, to understand and discuss its change occurred due to the urban development and to create new data on how public open spaces should be in future as a result of this discussion. Within this context, public space and public life have been studied as phenomena by discussing developmental processes of cities and the definition of these concepts have been examined. After the approaches evaluated, the relationship of the concept of public space with urban space has been discussed with the definitions given by theoreticians and architectures. The concept of public space has been defined physically and conceptually, based on the definitions offered by the literature. The changes in the concept of public space due to the urban development in historical process has been revealed through this definition. The change of public space has been evaluated based on domestic and foreign examples. The study has been concluded after it has been determined that the pandemic will 
increase the importance of the phenomenon of public space emphasized in this study and the need to public open spaces and the recommendations about public open spaces that will be designed in future.

Keywords: Public space, Urban public open space, Changes in the public space, Evolution of public spaces

\section{Giriş}

Küreselleşme, ekonomik gelişmeler, özelleştirmelerin ön plana çıkması, kentsel dönüşüm projeleri vasıtasıyla, kamusal alanlar son yıllardaki kent tartışmalarının en önemli maddesi haline gelmiştir (Madanipour, 2003, s.52) (Jacobs, 1961, s.35) (Hubbard, 1995, s.48). Kentsel mekânın kentli ile olan ilişkisi ve kentlinin faaliyetleri kamusallık ve kamusal yaşam için önem teşkil etmektedir. Bireyin kendini ifade ettiği, toplum ve fiziksel çevre ile ilişki kurduğu, ortak paylaşımda bulunduğu, etkileşime geçtiği alanlar, kentsel kamusal alanlardır. Günümüzde ortaya çıkan küresel salgınla birlikte, kamusal açık alanların önemi artmaktadır. Tarih boyunca salgınlar kentleri ve aktif olarak kullanılan kamusal açık alanları çok etkilemiştir. Bu araştırma, kamusal açık alanların değişiminin yönlerini ve günümüz kamusal açık alanlarının sağlıklı çevreler oluşturması için nasıl olması gerektiği sorularına odaklanmaktadır. Çalışma, sağlıklı çevrelerin oluşması için kamusal açık alanların düzenlenmesi ve tasarlanması için öneriler ortaya koymaktadır.

Çalışmada öncelikle, kamusal açık alanlara artan gereksinimin karşılanması ve değerlendirilmesi için kamusal alan kavramının tarihsel süreçte irdelenmesi gerektiği ele alınmıştır. Kamusal alan kavramı ve bu kavramın kentsel alanla nasıl bir araya geldiği literatür araştırması ile teorisyen ve mimarların tanımları ele alınarak, ortaya koyulmaktadır. Kamusal alan kavramı irdelendikten sonra, tarihsel süreçte hastalıklara karşı üretilen farklı kent modellerinin kamusal açık alanlara ve yeşil alanlara katkıları incelenmektedir. Kent modellerinin kamusal açık alanlara Kentlerde kır-kent ayrımının ortadan kalkması ve teknolojik gelişimlerin sonucunda kamusal alanların değişimi üzerinde durularak, bu değişimler ortaya çıkartılmıştır. Kamusal alanın değişiminin nedenleri ve sonuçları, tasarlanacak ve geliştirilecek kamusal açık alanlar yönünden önem arz etmektedir. Araştırılan ve incelenen örnekler değerlendirildikten sonra, sonuç bölümünde, sağlıklı çevreler oluşturabilmek için kamusal açık alanların düzenlenmesinde ve tasarlanmasında neler yapılması gerektiğine dair öneriler ortaya koyularak, çalışma tamamlanmaktadır.

\section{Kamusal Alan}

18. Yüzyılda tarihsel gelişmeler sonucunda ortaya çıkan kamusal alan olgusunu kavramak, kentlerin gelişimiyle ortaya çıkan değişimini anlamak ve tartışmak için bu kavramı tarihsel süreçte değerlendirmek gerekli görülmektedir.

Arendt kamusal alan kavramını tanımlarken, bireyler tarafından paylaşılan, buluşulan ve tartışılan ortak bir dünya olarak açıklamaktadır. Bu dünyada her bireyin kendine ait bir konumu ve aktif bulunduğu iletişim ve eylem alanı yer almaktadır. Arendt kamusa alan kavramını, etrafında oturan insanları bir arada tutan ve birbirleriyle ilişki kurmalarını sağlayan bir masaya benzetmektedir. Masanın ortadan kalktığı durumda, paylaşım ve iletişimin yok olacağını savunmaktadır (Arendt, 2012, s. 8-24). Habermas ise kamusal alanı, toplumsal yaşamın içinde, bireylerin tartıştığı, düşüncelerini dile getirdiği, herkes tarafından erişilebilen bir alan olarak tanımlamaktadır (Habermas, 
2000, s. 43-67). İki kuramcının bu kavramla ilgili ortak görüşü, insanların fikir ve eylemleri ile var olduğu ve içinde bulunduğu alan olmasıdır.

Sennett ise, bu kuramcılardan farklı olarak kamusal alanı, kentsel mekân ile ilişkilendirerek, ele almaktadır. Kamusal alanın işlevini kaybetmesinin üzerinde durarak, özele yönelmenin nedenlerini araştırmaktadır. Sennett, kapitalizmin etkileriyle, toplumsal ilişkilerin ve kamusal alandaki etkileşimin azaldığını ve bireyselliğe, aile ortamına dönüşün yaşandığını vurgulamaktadır. Bunun da yeni üretim ilişkilerini ortaya çıkararak, kamusal yaşamın gerilemesine sebep olduğunu açıklamaktadır (Sennett, 2002, s. 36-38).

Kentsel mekânda kavramsal içeriğinden sıyrılan kamusal alan, fiziki bir şekilde anlamlandırılabilmektedir. Kentsel mekânla ilişkilendirilen, kentsel kamusal alan, tarihsel süreç içerisinde sosyolojik anlamının yanında, fiziksel özellikleriyle çeşitlenerek, kentlinin bir arada bulunduğu, ortak aktivitelerini içeren, ortak olarak paylaşılan, toplumun her kesimine açık, fiziksel paylaşım alanıdır.

Gehl, kamusal alan ve gündelik yaşama yönelik faaliyetler üzerinde durmaktadır. Bu faaliyetlerin çeşitliliğinin, fiziksel çevre koşullarına bağlı olduğunu açıklamaktadır. Gündelik yaşantıda kamusal alanın kullanımının, isteğe bağlı, zorunlu ve sosyal faaliyetlerden oluştuğunu vurgulamaktadır (Gehl, 2004, s. 97-102).

Madanipour, kamusal alan tanımını, fiziksel olarak erişilebilen, toplumsal etkileşimin ve faaliyetlerin herkese açık olduğu alanlar olarak açıklamaktadır (Madanipour, 2003, s. 42). Lynch de bu görüşe paralel olarak, insan faaliyetlerinin dış mekan yaşantısında önemli olduğunu öne sürerek, insan ilişkisinin oluşturulduğu alanların tasarlanması gerektiğini savunmaktadır (Lynch, 1981, s. 27-35). Carmona ve Carr da aynı görüşle, fiziksel çevreyi etkileyen en önemli etmenin insan faaliyetleri olduğunu ileri sürmekte ve kamusal alanı gündelik faaliyetlerin gerçekleştiği ortak alan olarak tanımlamaktadır (Carmona, 2010, s. 22) (Carr, Francis, Rivlin, \& Stone, 1992, s. 56). Jacobs da, kamusal alanın kentlinin aktiviteleriyle geliştiği toplumsal ortak bir alan olduğunu savunmaktadır (Jacobs, 1961). Whyte, kentin aktif kullanımının kamusal alanlar aracılığıyla olduğunu ve bu alanların kentlinin günlük faaliyetlerini barındırdığını vurgulamaktadır (Whyte, 1980). Thompson'a göre, kamusal açık alanlar, barındırdıkları yeşil alanlar ve bitki örtüsüyle, sağlıklı çevre ve mikro-klima sağlayarak, ekolojik ortam oluşturmaktadır (Thompson, 1998). Kamusal açık alanlar, kentlinin fizyolojik ve psikolojik intiyaçlarını gidererek, rahat ve konforlu alanlar sunmaktadır (LouikatouSideris, 1996, s. 26).

Araştırılan tanımlamalarla, kavramsal literatürde Arendt, Habermas ve Sennett'in söylemlerindeki kamusal alan, kendini ifade edebilme, etkileşim içinde olma düşünceleri ile teorisyen ve mimarların tanımlarındaki kamusal alan, faaliyet, kullanıcı ve kullanım ilişkisi bir araya getirilmiştir. Genel anlamıyla, kamusal alan, kavramsal olarak düşünüldüğünde fikir ve eylemin öne çıktığı, fiziksel olarak baktığımızda da bir arada olmayı sağlayan, kullanım, kullanıcı ve faaliyet ilişkisinin bulunduğu alandır.

\section{Kent Modelleri}

Sağlıklı çevrelerin oluşturulması için farklı kent modelleri üzerine birçok çalışma yapılmıştır. 19. Yüzyıl endüstri kentinde hızıı kentleşme yaşanmıştır. Hızlı kentleşme ile birlikte nüfus yoğunluğu sağlıksız çevrelerin oluşmasına sebep olmuştur. Howard 18891892 yılları arasında, geleceğin bahçe şehri yaklaşımıyla, sağlıksız kentlerle, kırı bir araya getirmeyi önermiştir. Bahçe şehir şemalarıyla, kır ve kentin avantajlarını bir araya 
getirmeyi öngörerek, nüfus yoğunluğuna ve çevre kirliliğine çözüm üretmiştir. Planın ana çıkış noktası, kır hayatının doğal koşullarının kente, kent hayatının toplumsal işlevlerinin ise, köye taşındığı, karşılıklı dayanışmaya dayalı bir yerleşim yeri yaratmaktır. Bu şemalar, nüfusun yoğun olduğu çalışma alanlarını, kırsal alanlar ve kentsel ağ ilişkisi içinde yeniden organize etmeyi hedeflemektedir (Howard, 1965, s.38). Kırsal alanlarda insanların tarım ve hayvancılık yapacağı alanlar, orman alanlarının korunması, üretimin kentsel alanların içinde düzenlenmesi sağlanmıştır.

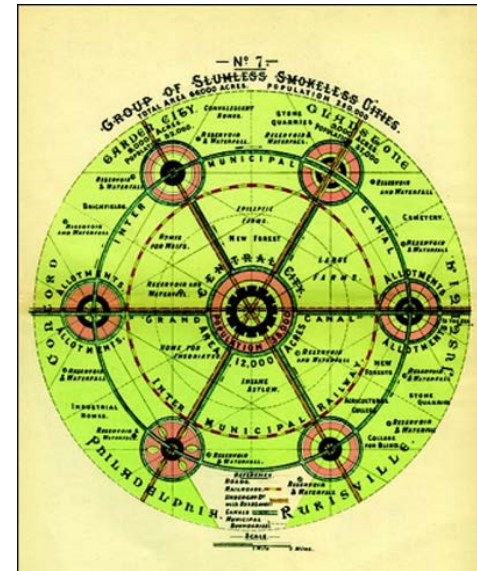

Şekil 1: Bahçekent plan şeması (Howard, 1965, s.42)

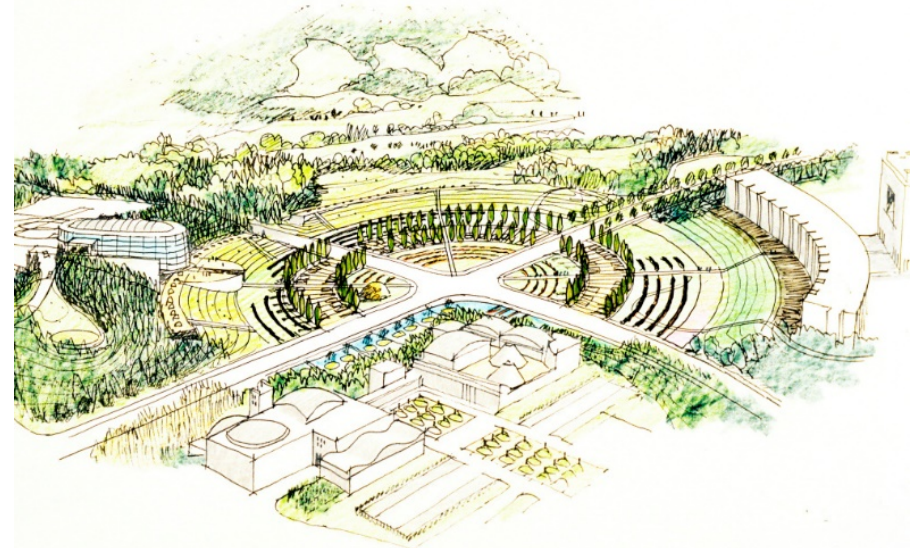

Şekil 2: Bahçekent eskiz çalışması (Howard, 1965, s.42)

Önerilen bahçe kentler, sınırları belirli, merkezcil, simetrik ve kompakt bir yapıdadır. Nüfusu 32.000 olan bahçe kentler yeşil alanın içinde yollarla bağlanmakta, içinde yaşayanların günlük intiyaçlarını karşılayacak ekonomik, sosyal ve kültürel kamusal alanları bulundurmaktadır. Merkezde bulunan 52.000 nüfuslu büyük bahçe kent ise, küçük kentlerin içinde barındırmadığı sosyal donatıları barındırmaktadır. Howard bu yeşil bağlantı alanlarının, kamu mülkiyetinde olup, kamusal alanlar olarak kullanılmasını sağlamıştır. Bu önerilerle nüfusu desantrilize edip, kırı ve kenti bütünleştirmeyi amaçlamıştır. Yeşil yürüyüş alanları, sosyal merkez, okul, büyük parklar bu önerinin içinde bulunmaktadır. Bahçe kent yaklaşımıyla, sağlıklı, temiz hava ve güneş ışığı alan, doğayla iç içe, yeşil yaşam ve sosyal alanlar sunmaktadır. Yeşil alanlar ve sosyal yaşamı bir arada bulundurarak kamusal alanların sürekliliğini sağlamaktadır (Şekil 1-2).

Bahçe kent modelinin kır hayatıyla kent hayatını bir arada tutma fikri, 20. yüzyıl boyunca kent plancılarında çok etkili olmuştur. Howard'ın modeli üzerinden bahçe şehir uygulamaya geçmiştir. Welvyn bahçe şehri hava kirliliğinin olduğu kentlerden, sağlıklı güneşli ortamlara taşındığı bir model önerisidir (Fot. 1-2). Bu bahçe şehir halen yaşam çevresi olarak varlığını korumaktadır. Bu modelde, kır ve kent, yeşil alanlar, küçük tarım parselleri, konut alanları iç içe geçmiş durumda uygulanmıştır. Howard'ın ileri sürdüğü, her evin bir bahçesi olması ve bahçelerin bütün bir yeşil ile birbirine bağlanarak yeşil koridorların oluşturulması fikri uygulanmıştır. Bu yeşil koridorla Howard, hem evlerin kendine özel bahçelerini birbirine bağlamış, hem de ortak yeşil paylaşım alanları ile kamusal alanları oluşturmuştur. 


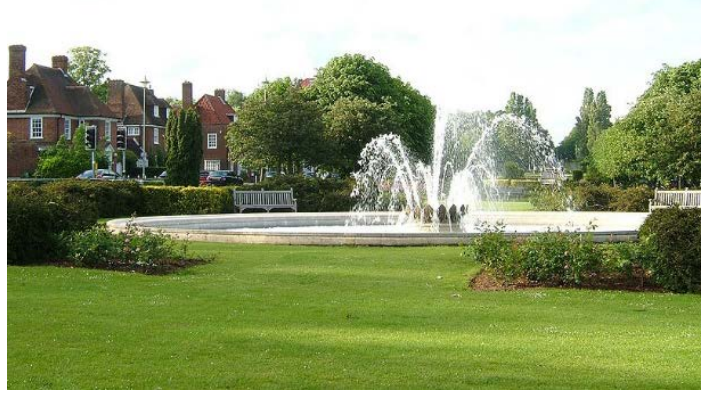

Fot. 1: Welvyn Bahçe Kenti (URL-1)

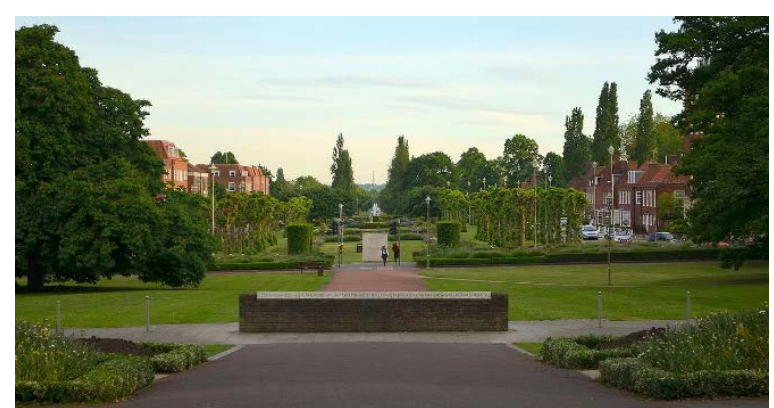

Fot. 2: Welvyn Bahçe Kenti (URL-1)

Londra'nın kentsel büyümesi 1843 yılında kompakt bir yapıdayken, 20. Yüzyılın başında genişleme, saçaklanma ve yoğunlaşma yaşanmıştır. İkinci dünya savaşı sonrası, bahçe şehir modeli, uygulamaya geçilerek, birinci model planlama aracı olarak yeşil kuşak Londra kenti çevresinde önerilmiştir. Dolayısıyla kentin büyümesi sınırlandırılmıştır. Yeşil kuşağın ötesinde de yeni bahçe kentler planlanmıştır (Özdeş, 1985 , s. 38-49). Oluşturulan yeşil kuşaklar ile yeşilin yoğun olduğu kamusal alanlar tanımlanmıştır.

İkinci model sağlıksız kentleri sağlıklı hale getirmeye yönelik olan, Le Corbusier tarafından, 1925 yılında Paris kentinin merkezi içinde en yoğun bölgede önerdiği Plan Voisin önerisidir (Şekil 3-4). Howard'in modelinden farklı olarak, yüksek yoğunluklu planlanmış, kent merkezinde konumlandırılmıştır. Plan, yoğunluğu aynı tutarak geniş yeşil alanları kentin merkezine getirmeyi hedeflemiştir (Özer, 1987, s.22). Corbusier, yatay büyüme yerine yoğunluğu düşey yüksek bloklarda kullanmıştır. Modelde, yüksek konut ve ofis blokları yeşil alanlarla çevrili olarak düşünülmüştür. Ancak, Corbusier'in oluşturduğu öneri ile otoyol ve otoparklar, kamusal alanların sürekliliğini yok ederek, geniş ve parçalı boşluklar oluşturmuştur. Bu durum, kamusal alanların bütün olarak davranmasının önüne geçmiştir.

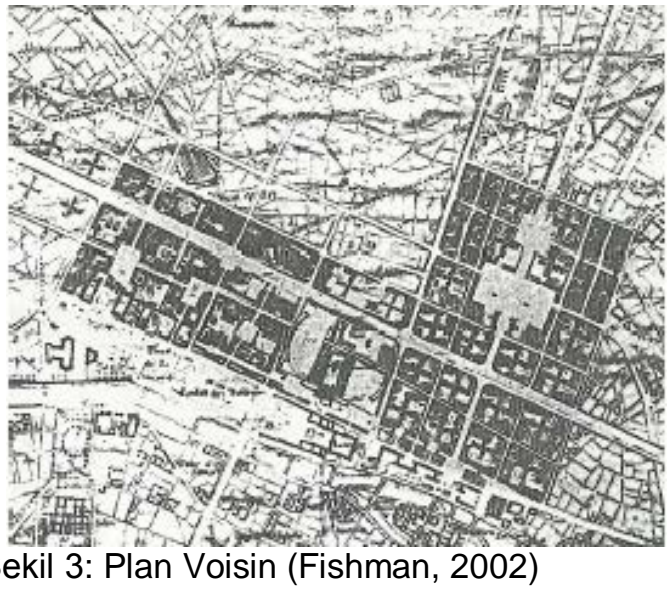

Şekil 3: Plan Voisin (Fishman, 2002)

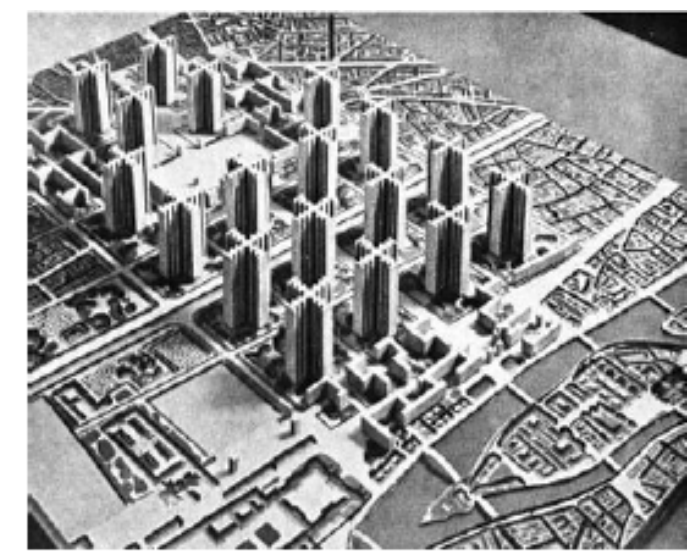

Şekil 4: Voisin Plan üç boyutu (Fishman, 2002)

Corbusier'in 1930 yılında geliştirdiği bir diğer kent modeli, ışıyan şehir, kamusal açık alanların, yeşilin bulunduğu sağlıklı kentler üretme fikridir (Şekil 5-6). Belirli bir nüfus yoğunluğunu en sağlıklı bir şekilde oluşturmaya yönelik kentsel model önerisidir. Parklar içerisinde yüksek konut ve ofis blokları, sosyal donatıların yer aldığı kamusal alanları içermektedir. Bu modelle, teknolojik gelişmeleri ele alarak, kentin çeperindeki saçaklanmaya, taşıt bağımlılığına, sanayinin kentsel mekânı olumsuz etkilemesine ve güvenlik sıkıntılarına çözüm getirmeyi amaçlamıştır. Tanımladığı işlevlerle alanı 
bölgelere ayırmıştır (Fishman, 2002, s. 37-46). Corbusier'in bu önerilerinin gerek toplu konut alanlarında gerekse özel konut alanlarında halen etkili olduğu düşünülmektedir.

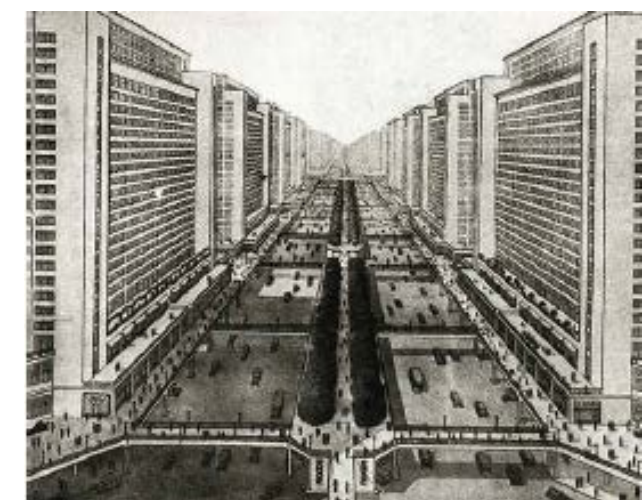

Şekil 5: Işıyan Şehir perspektif görüntüsü (Fishman, 2002)

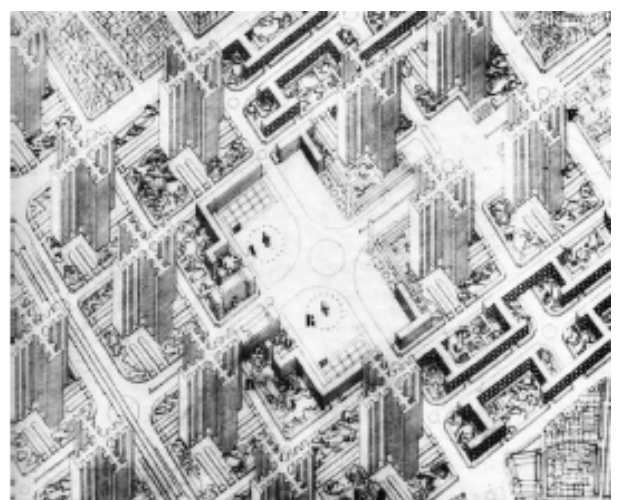

Şekil 6: Işıyan Şehir üç boyutu (Fishman, 2002)

Corbusier'in 1946-1952 yılları arasında yaptığı Unité d'Habitation projesi ile insanları en sağlıklı şekilde bir arada yaşatabilmek için, zeminin açılması, yeşil alanlara bırakılması, trafik ve yaya yollarının bir birinden ayrılması, insanların güneş almasının sağlanması önerilmiştir (Fot.3). Salgına karşı tedavi için insanların kamusal alanlarda temiz hava ve güneş ile buluşmasını amaçlamıştır. Chandigarh planında, Corbusier fikirlerini geliştirerek, grid içerisinde yeşil yürüyüş koridorları oluşturmuştur. Kamusal alanlar yürüyüş koridorlarını içine alarak, yeşilin içinde okul, sosyal donatılar ve yaya yolları konumlanmaktadır (Fot.4) (Girardet, 1996, s.27). Kamusal açık alanlarla yeşilin bir arada bulunduğu sağlıklı şehir pradigmasının, 1950'lerde yapılan planda da var olduğu görülmektedir.

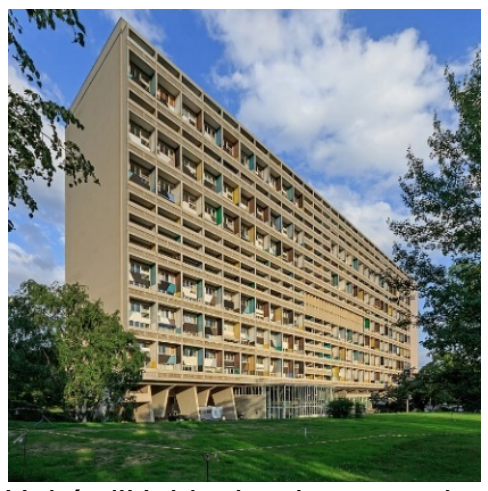

Fot. 3: Unité d'Habitation konut projesi (URL2)

Üçüncü model, 1932-1935 yılları arasında Wright tarafından önerilen Broadacre City, yoğunluğun bütün alana dağıtılı̆̆ı, kent merkezinin olmadığı, grid yollar sistemi üzerinde konut alanlarının, kentsel kamusal kullanımların, donatıların yayıldığı, kır ve kentin iç içe geçtiği bir plan şemasıdır (Şekil 7-8) (Fishman, 2002, s. 37-46). Kent kırdan ayrı değil, kent ve kır bir arada, bireysel yaşam önerisi sunmaktadır. Bu modelde, kara ulaşımı, demir yolları, spor alanları, fabrikalar, ofis blokları, konutlar, otoyol sistemi yer almaktadır. İhtiyaç oldukça büyüyebilecek, kentin sınırlarının belli olmadığı bir modeldir. Belirli bir bölgelenme yapılmamıştır. Ulaşım bireysel araçlara dayanmaktadır. Ailenin kendi kendine yetebildiği, tarım yapabildiği alanların bulunduğu, kırın erişilebilir olduğu bir plan yaklaşımıdır. ABD'nin yaşam biçiminin bu modeldeki desantrilizasyona yönelik olduğu ve bireysel bir yaşam biçimini destekleyen, kentlerin 
çevresinde banliyölerin geliştiği görülmektedir. Bu model önerisi ile kamusal açık alanların sürekliliği zedelenerek, kent merkezinin dışında parçalı alanlar oluşmuş ve kamusal alanların bütünlüğü bozulmuştur.

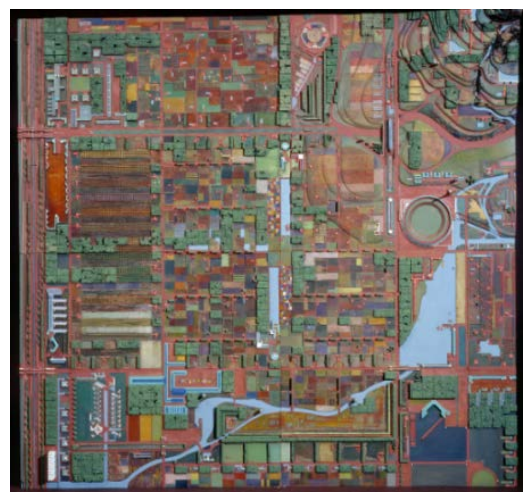

Şekil 7: Broadacre Kenti planı (Fishman, 2002)

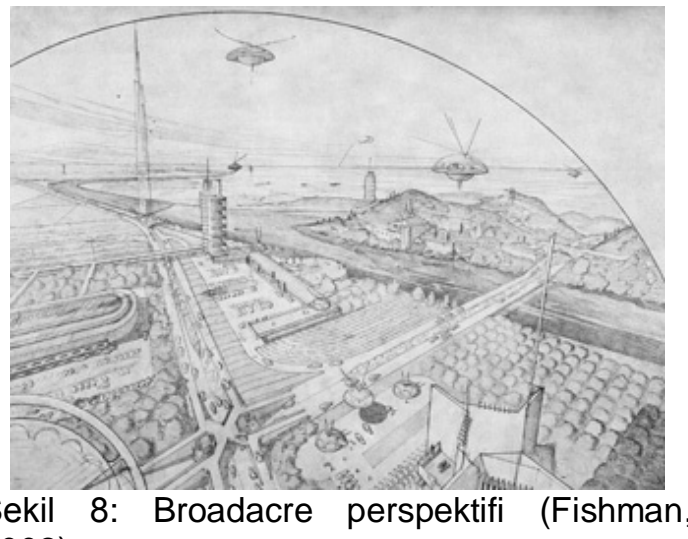

2002)

1950 'lerin sonundan itibaren kent merkezlerinin gelişmelerden olumsuz etkilendiği savunulmaktadır. Bu dönemde, kent merkezi ve kent merkezinin yoğunluğu tartışılmaya başlamıştır. 1960'ların ütopyalarında, teknolojinin kullanımı, yoğun olarak insanların bir arada yaşadığı yeni kent modelleri, mevcut kentin üzerinde mega strüktürler içerisinde konutlar yer almaktadır (Şekil 9-10).

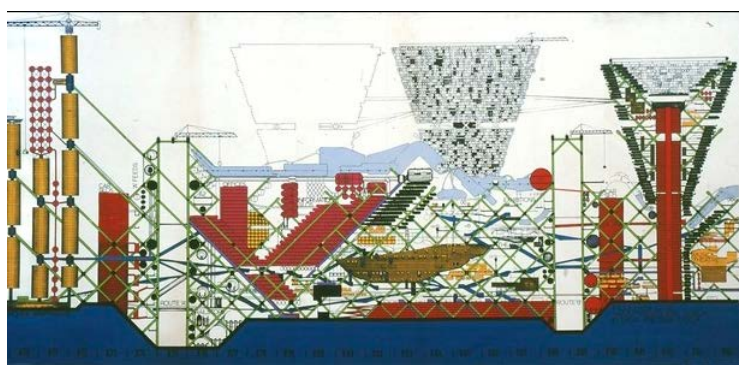

Şekil 9: Archigram, Plug-in City, 1964 (Sadler, 2005)

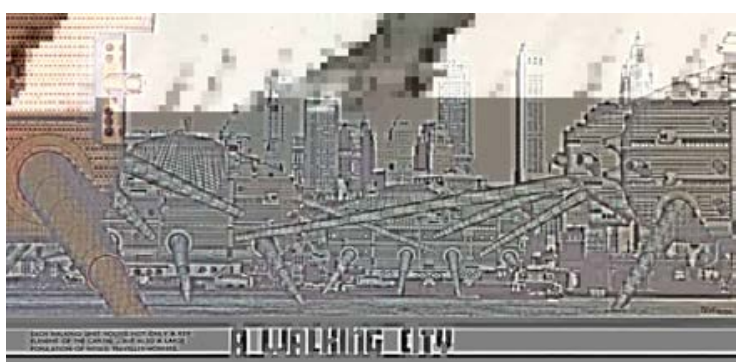

Şekil 10: Archigram, Instant City, 1968 (Sadler, 2005)

Bu ütopyalarda, modernist ütopyanın devam ettirilerek, temiz hava ve güneşin halen düşünüldüğü görülmüştür. Ütopya düşünceleri, kenti yeniden çeperlerde dağıtmak, yoğunluğu azaltmak, sağlıklı hale getirmek için yeşil alanlar içerisinde konut blokları düşüncesi 1960'lardan itibaren yoğun olarak tartışılmaya başlanmıştır. Jane Jacobs, kent merkezlerindeki yaşamın önemi üzerinde durarak, desantrilizasyonun, modern konut alanlarının kenti yok ettiğini vurgulamaktadır. Belirli bir nüfusun etkileşimi ile kent merkezinin yaşamasının sağlanabileceğini savunmaktadır (Fishman, 2002, s. 37-46). Kent merkezi dışında oluşturulan yaşam alanları, kent merkezinde bulunan kamusal alanların değerinin yitirilmesine sebep olmuş, yeni tasarlanan alanlarda farklı kamusallıkları beraberinde getirmiştir (Şekil 11-12). 


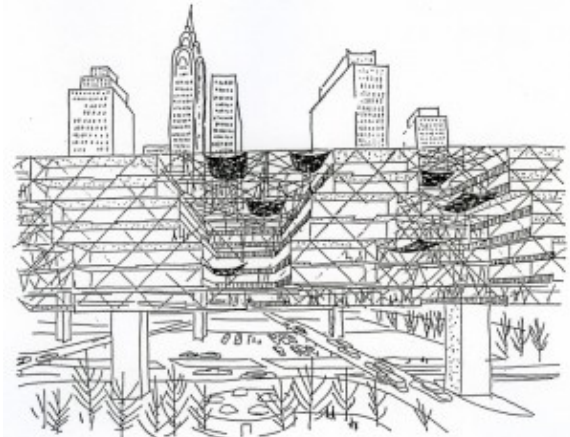

Şekil 11: Ville Spatiale, Yona Friedman, New York, 1964 (URL-4)

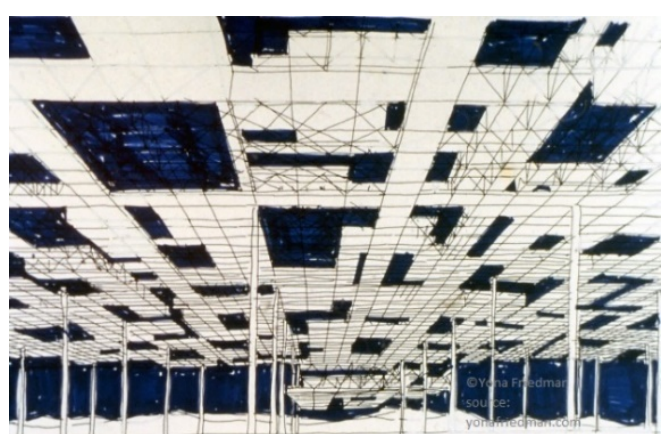

Şekil 12: Ville Spatiale, Yona Friedman, New York, 1964 (URL-4)

20. yüzyılla birlikte, ekoloji alanındaki gelişmeler ve kentlerde yaşanan sorunlar karşısında doğayla iç içe ekolojik kentler düşünülmeye başlanmıştır. Büyük Paris Metropol Alanını yeniden düşünmek üzerine yapılan yarışmada, sürdürülebilirlik, kentin çevresindeki yeşil alanlarla, tarım alanları ve orman alanlarıyla birlikte yaşaması gerektiği düşüncesi yeniden önem kazanmıştır (Şekil 13). Merkezin yoğun olduğu bölgede, kentin desantirilizasyonu, çok merkezli yapının gerçekleştirilmesi için yeşil alt yapının sağlanması, yeşil sürekliliklerinin korunması, yaşanabilir, sağlıklı, doğayla barışık kentler üretebilmek için çalışmalar yapılmıştır (Fishman, 2002, s. 37-46). Kamusal açık alanlar yeşil ile birlikte düşünülmüştür.

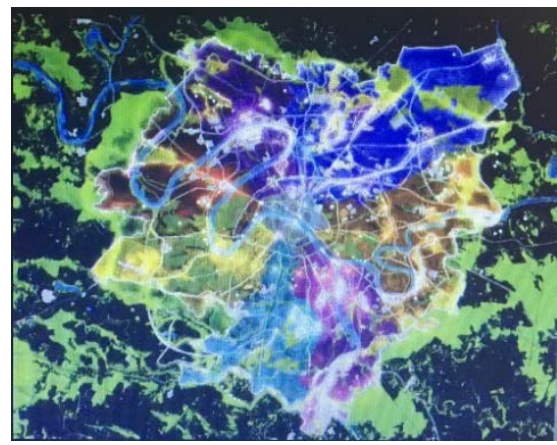

Şekil 13: Paris Metropol Alanı Düzenlemesi (Fishman, 1996)

Fishman, 19. yüzyılın ikinci yarısından itibaren, Paris, Berlin, Londra gibi Avrupa Kentlerinin nüfus yoğunluğunun artarak, kırsal alana doğru sağlıksız koşullarda saçaklandığını vurgulamaktadır. Kent ve kır ayrımının arttığını, kent merkezlerinin ve kamusal alanların doğadan uzak kaldığını ileri sürmektedir (Fishman, 2002, s. 48-54).

Salgınlarla birlikte, kent merkezleri ve kamusal açık alanlar giderek daha da terkedilmiş, üst gelir grupları tarafından merkezin dışında çeperlere doğru yeni gelişen yaşam alanları oluşturulmuştur. Bu durum çok merkezli kentlerin oluşmasında etkili olmuştur. Çok merkezli kentlerin oluşumu kent merkezinden bağımsız, kendi içinde sürekliliği olmayan kamusal açık alanları beraberinde getirmiştir.

\section{Kamusal Alandaki Değişimler}

Kentlerdeki ekonomik farklılaşmalar, üretim biçimlerinin değişmesi, toplumsal değişiklikler kamusal alanların değişmesine sebep olmaktadır. Ekonominin değişmesi, kentlerin farklı şekillenmesini, yaşam tarzlarının değişmesini, kamuya ait yatırımların azalmasını, özel yatırımla biçimlenen kentsel mekânların oluşmasını beraberinde 
getirmektedir (Fot.5-6). Yetersiz yeşil alan ve ulaşım ağı altyapısı, plansız yerleşimler sağlıksız çevrelerin oluşmasına neden olmakta, kentlilerin yaşam kalitesini olumsuz yönde etkilemektedir.

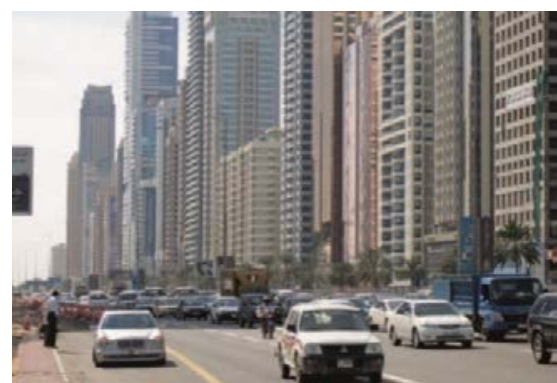

Fot.5: Dubai'deki yüksek binalar (Gehl, 2010, s.45)

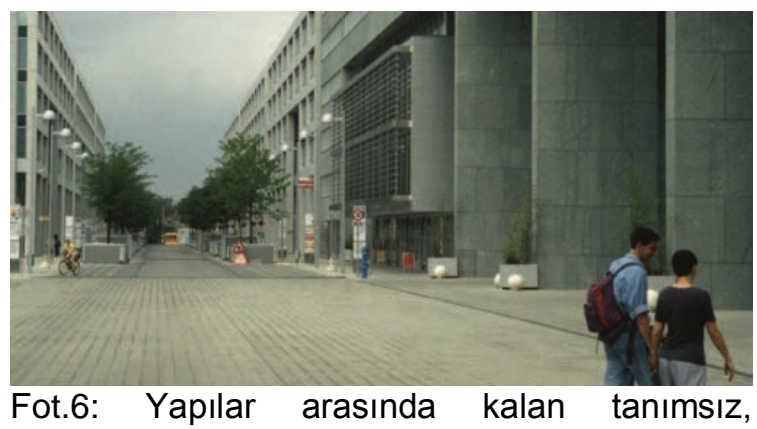

kullanılmayan boşluklar (Gehl, 2010, s.45)

Kent merkezlerinin desantrilizasyonu, taşıt yoğunluğu, toplumsal ve ekonomik ilişkilerin değişmesi, günümüzün kamusal alanlarının kullanım ve biçiminde değişikliklerin yaşanmasına sebep olmuştur. Özel mülkiyette şekillenen ticari alanlar, kamusal alanların ekonomik rolü üstlenmesini sağlamıştır. İşlevlerin özelleşmesi, kamusal alanların özel alanlara dönüşmesine neden olmuştur (Fot.7-8-9). Bu alanların tasarım, yönetim ve kontrolü kamudan özele geçerek, kamusal alanlar tüketim odaklı kentsel alanlara dönüşmektedir (Fishman, 2002, s. 67-72).

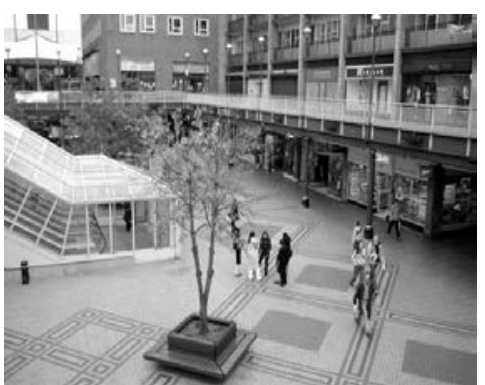

Fot.7: Coventry Kent Merkezi - Özel Alan, İngiltere (Carr, Francis, Rivlin, \& Stone, 1992, s.32)

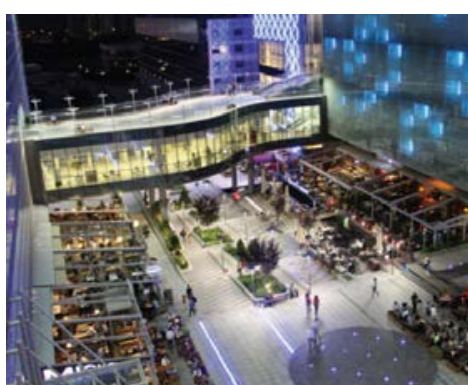

Fot. 8: Armada Alışveriş Merkezi, 2019 (URL-5)

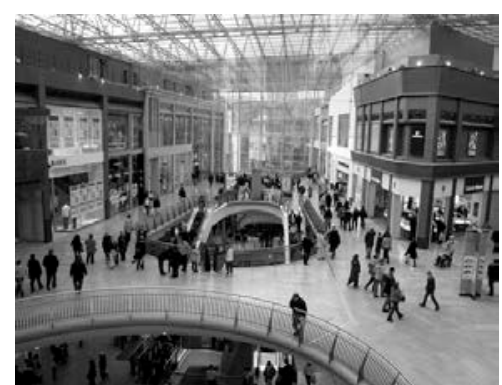

Fot. 9: Özel Alan - Alışveriş Arkadı (Carmona, Magalhães, \& Hammond, 2008, s.24)

Kent merkezlerinin terkedilmesi, çeperlerin genişlemesi ve saçaklanmalar, kentsel mekânın sınırlarını ortadan kaldırmaktadır. Kentsel saçaklanmalar, toplumsal ayrışmalara ve mekânsal parçalanmalara sebep olmaktadır. Kentlerin çeperlerinde, yeni yerleşimler, ticari alanlar oluşmaktadır (Kalinski, 1999, s.51) (Carr, Francis, Rivlin, \& Stone, 1992, s. 44). Bu alanlara ulaşmak için, yollar, üst geçitler oluşturulmuş, kentsel mekân parçalanmıştır. Taşıın kenti hâkimiyeti altına alması, kamusal alanların yerini taşıtlara bağlı alanların oluşması, kentte kırsal alanların parçalanmasına, sağlıksız ve güvensiz ortamların oluşmasına sebep olmuştur (Fot.10-11-12). 


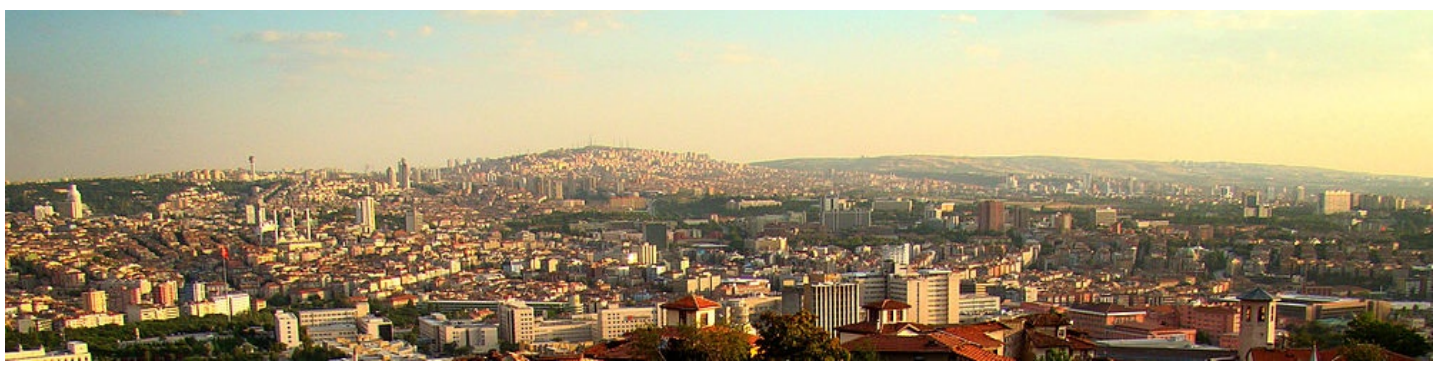

Fot. 10: Ankara kent merkezi dışındaki yeni oluşumlar (URL-6)

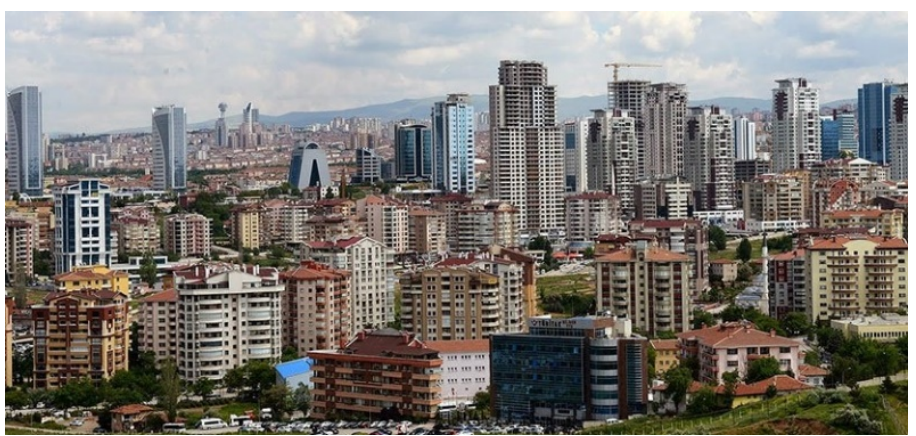

Fot. 11: Ankara - Eskişehir Yolu ve çevresi kentsel parçalanma (URL-7)

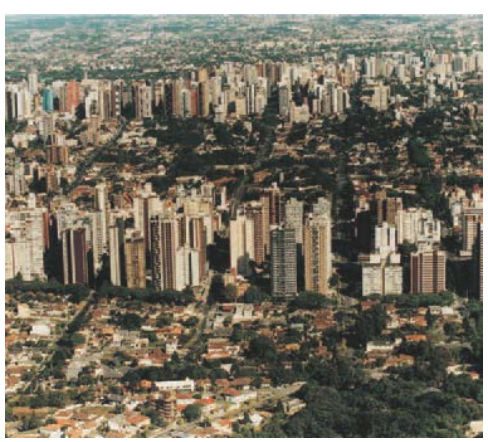

Fot. 12: Curitiba, Brezilya (Gehl, 2010)

Kentlerde kır-kent ayrımının ortadan kalkması, doğal alanların ve tarım alanlarının yok olmasını beraberinde getirmiştir. Özel mülkiyet içinde oluşturulan yeni kamusal alanlar, hem kullanıcı hem de kullanımları ayırarak, kamusal yaşam intiyaçlarını farklılaştırmaktadır. Bu alanlar topluma hitap etmek yerine, bireysel kullanımlara dönüşmekte, kapalı alanlarda hizmet vermektedir. İçe dönük tasarlanan bu yapılar, kentlinin güneş ve açık havadan mahrum kalmasına sebep olmaktadır. Bu durum sağlıklı çevrelerin yaratılmasını engellemektedir (Fot.13-14-15).

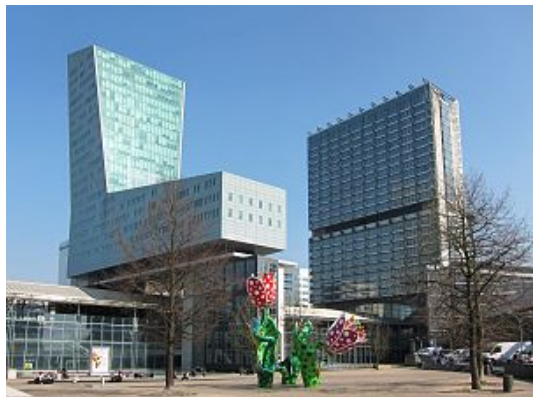

Fot. 13: Eurolille, Lille, Fransa (Gehl, 2010)

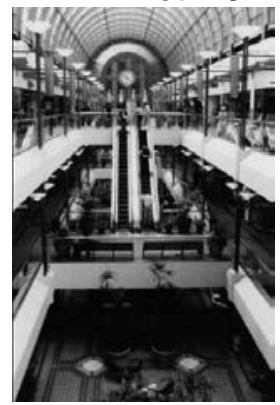

Fot. 14: Özel alan - alışveriş arkadı (Carmona, de Magalhães, \& Hammond, 2008)

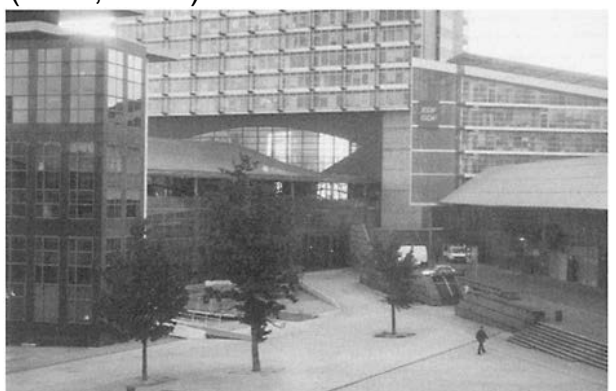

Fot. 15: Özel Alan, Lille, Fransa (Madanipour, 2003) 
Kamusal alanların özelleşmesi, kamusal yeşil alanların ve meydanların yok olmasına veya yeniden tasarlanarak, güvenlik önlemlerinin bulunduğu yapay çevrelere dönüşmesine yol açmıştır (Punter, 1990, s. 21) (Sadler, 1993, s.24). Modern ofis kulelerini çevreleyen batık bazalar ya da plazalar kentsel çevrenin ticarileştiği tasarımlar olmaktadır. Kamusal ve özel yaşam üzerine çalışan Sennett, modern dönemle birlikte, yeni kapitalist kent kültürünün oluşumundaki kamusal yaşam düşüşünü vurgulamaktadır (Sennett, 2002, s.36). Kamusal yaşamdaki bu düşüş ve kamusal alandaki değişimler, sokak, meydan ve yeşil alanların yerini yeni yaşam merkezlerinin almasına neden olmakta ve kentin kamusal alanları terkedilmektedir. Bu durum, kent merkezlerinin güvensiz ortamlara dönüşmesine, sağlıksız çevrelerin oluşmasına neden olmaktadır (Fot.16-17).

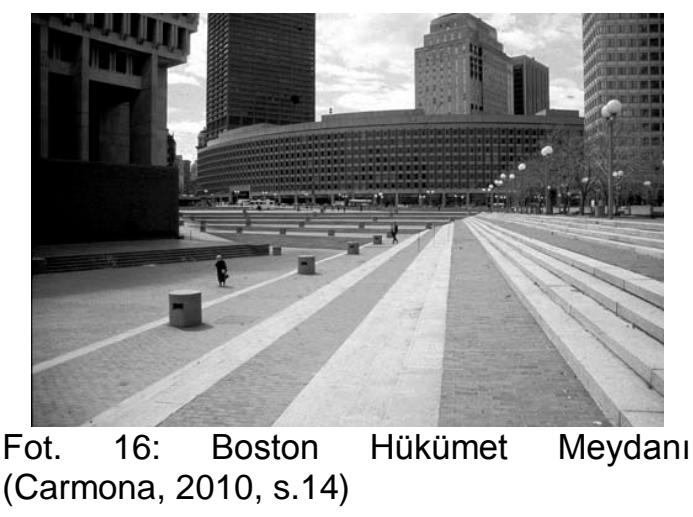

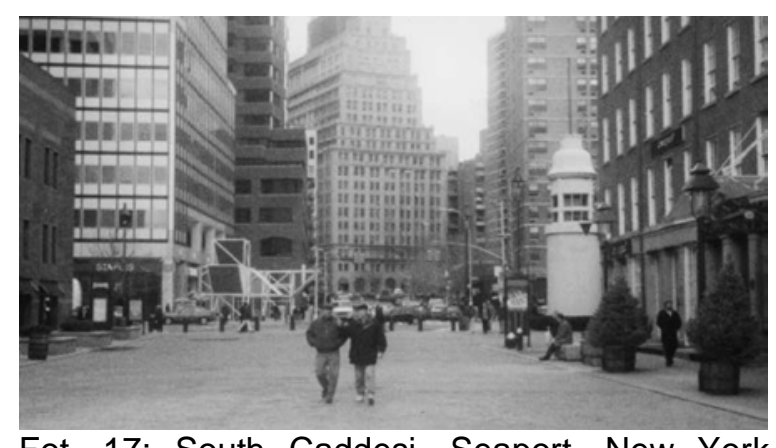

Fot. 17: South Caddesi, Seaport, New York (Banerjee, 2001, s.7)

Merkez işlevi yüklenen kent çeperlerindeki alanlar, kent dokusu oluşturmaktan çok, taşıt ulaşımına bağlı, otopark alanları ile çevrili, yeşil alanlardan yoksun, içe dönük yapılaşmalar barındırmaktadır. Bu yeni yapılaşma modeli ile tek bir yapı içerisinde farklı ticari faaliyetleri barındıran mekânlar oluşmakta, çevresiyle bir bütün oluşturacak kentsel çevreler yaratılmamaktadır. Mülkiyete dayalı tasarımlar, yeşil alanların sürekliliğinin bozulmasına, kentsel mekânda bakım ve yönetim sorunlarına sebebiyet vermektedir. Kamusal ve özel alanlar arasındaki belirsiz ayrım, kullanılmayan tanımsız alanların oluşmasına neden olmaktadır (Fot.18-19-20).

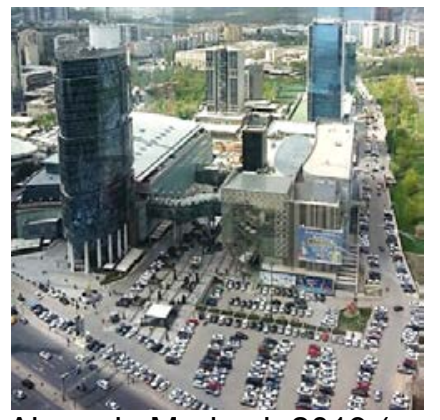

Fot. 18: Armada Alışveriş Merkezi, 2019 (yazarın arşivinden) 


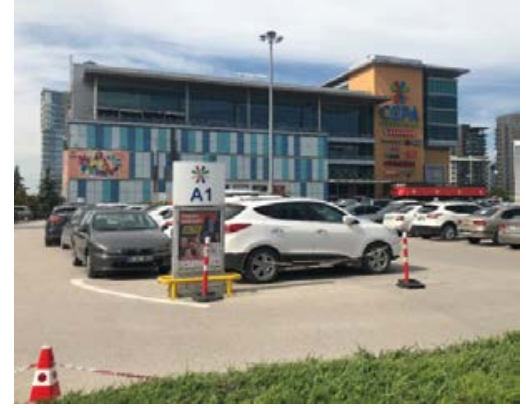

Fot. 19: Cepa Alışveriş Merkezi, 2019 (yazarın arşivinden)

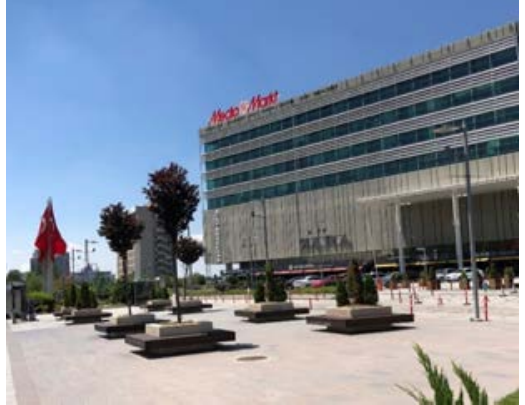

Fot. 20: Kentpark Alışveriş Merkezi, 2020 (yazarın arşivinden)

Salgınla birlikte kamusal alan olgusu, ortak, paylaşılan fiziksel alanlardan, yeni teknolojilerin ön plana çıktığı sanal ortamlara evrilmiştir. Bu durum, kamusal alanın anlamının yanında biçiminin de şekil değiştirdiğini göstermektedir. Fiziki mesafenin sağlanamadığı dar yaya yolları ve sokaklar, toplu ulaşım ağlarının yoğunluğu, yetersiz yeşil alanlar, yapı yoğunlukları ve plansız yerleşimler, bakımsız, sahipsiz ve yönetilmeyen kamusal alanların salgın süreciyle birlikte yeniden düzenlenmesi gerekliliği ortaya çıkmıştır. Kentsel mekânda kamusal açık alanların ve yeşil alanların düzenlenmesi, kentsel alandaki iletişim ve etkileşim sorununu çözerek, insan faaliyetlerini kapsayan sağlıklı çevrelerin yaratılmasını sağlayacaktır.

Salgın döneminde, kentlinin günlük yaşam pratikleri değişmiş, yürüyüş yapmaya, bisiklete binmeye, kamusal açık alanlara ve yeşil alana daha çok gereksinim duymuştur. Yurtdışında ve ülkemizde bu intiyaçlara yönelik yeniden yapılandırma çalışmaları başlamıştır. New York'ta bazı yollar kapatılarak, yaya yolları genişletilmiş, bisiklet yolu şerit sayıları arttııılmıştır (Holmes, 2020, s.23). İtalya Milan'da bazı ana yollar yürüyüş ve bisiklet için kapatılarak, taşıtlara alternatif ulaşım için elektrikli scooterların kullanımı sağlanmıştır (Fot. 21-22) (URL-8).

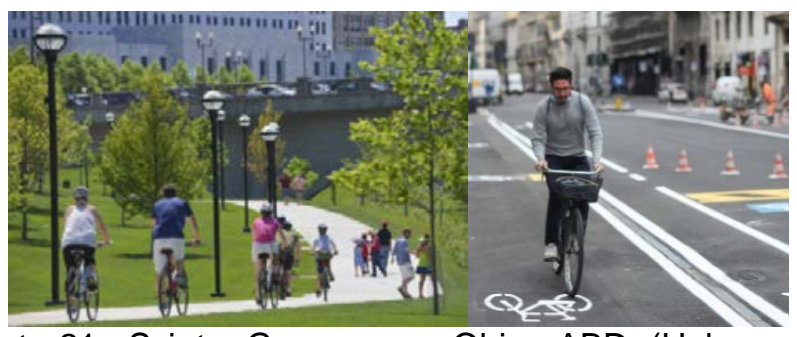

Fot. 21: Scioto Greenways, Ohio, ABD (Holmes, 2020, s.32)

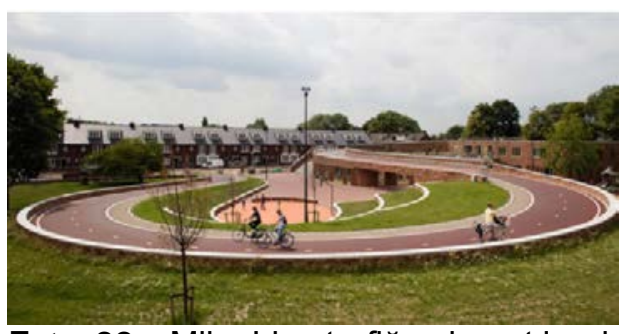

Fot. 22: Milan'da trafiğe kapatılarak düzenlenen bisiklet şeridi (URL-8)

Yapılan çalışmalarda, kentlinin kentsel açık alanlarda daha fazla zaman geçirme, yeşil, doğal çevre ile iç içe olması için, yeşil alanlarda sosyal mesafe korunarak, spor faaliyetleri, dinlenme ve zaman geçirme alanları yaratılmıştır. Brooklyn'de yeşil alanların kentli tarafından kullanılması için, 2.4 metre çapında sosyal mesafe daireleri oluşturulmuş, böylece kamusal açık alanlarda güvenli, konforlu, doğa ile bütünleşik kaliteli zaman geçirilmesi sağlanmıştır (Fot. 23-24) (URL-9). 


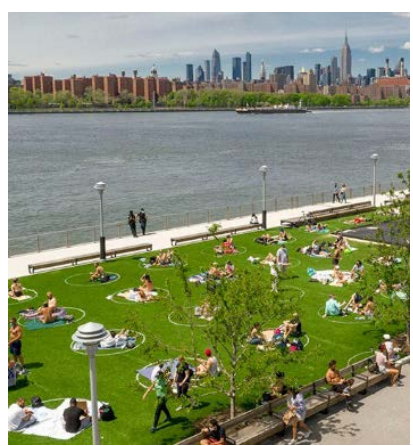

Fot. 23: Brooklyn, New York Domino Park (URL-9)

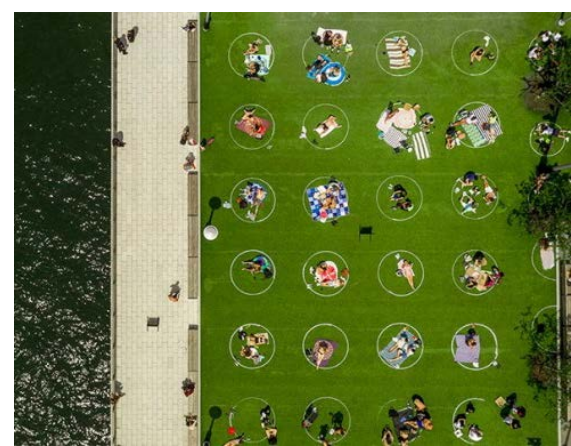

Fot. 24: Brooklyn, New York Domino Park sosyal mesafe daireleri (URL-9)

Bu uygulamanın benzerleri ülkemizde İstanbul, İzmir ve Mersin'de yeşil alan kullanımı için uygulanmıştır. Böylece kamusal açık alanların kentli tarafından sosyal mesafe kuralları çerçevesinde, kontrollü bir şekilde aktif kullanımı sağlanmıştır (Fot. 25-26).

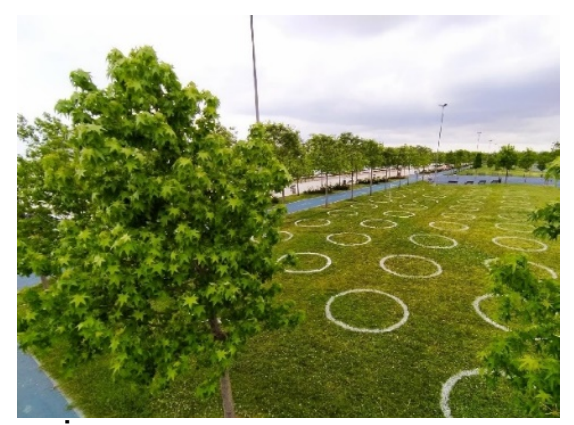

Fot. 25: İstanbul'da Anadolu yakasındaki yeşil Fot. 26: İzmir Karşıyaka Sahili (URL-10) alan (URL-10)

\section{Sonuç ve Öneriler}

Günümüzde, teknolojik gelişmeler, sanayileşme, nüfus yoğunluğu, kentlerin plansız büyümesi, altyapı sıkıntısı, çeperlerdeki saçaklanmalar kentlerde birçok sorunu ortaya çıkarmış, kentlinin yaşam kalitesini olumsuz etkilemiştir. Kamusal açık alanlar, hızlı değişim sürecinde parçalanarak, kullanılmayan alanlara dönüşmüş, ya da yeniden düzenlenerek ticarileşmiştir. Tüm dünyada yaşanan küresel salgınla birlikte kamusal açık alanlara gereksinimin her geçen gün daha da artacağı açıktır. Kentsel kamusal açık alanlar, kent yaşamı ve insan etkinliklerini çeşitlendirme rolü içermektedir. Kentsel kamuya açık alan, kent işlevi, kent imgesinin oluşturulması, yaşam kalitesinin iyileştirilmesi ve çevre niteliklerinde etkilidir. Kentlinin fiziksel ve psikolojik ihtiyaçlarına karşılık veren, herkes tarafından erişilebilen kamusal açık alan ve yeşil alan düzenlemeleri kent planlamasında tasarlanması gereklidir.

Sağlıklı çevreler yaratmak ve yaşam kalitesini arttırmak için, kamusal açık alanlar tasarlanırken ve düzenlenirken;

- kentsel dokuyla ilişkili yeşil koridorlar oluşturmak,

- yeşil koridorlara takılı yürüyüş bağlantıları,

- bisiklet yolları,

- sosyal donatı alanları oluşturmak,

- yaya dolaşımını sağlamak,

- konforlu ve güvenli alanlar oluşturmak,

- ekosistemin sürdürülebilmesi,

- kişi başına düşen nitelikli yeşil alan miktarının arttıııması, 
- yeşil ağların sürekliliği

göz önünde bulundurulmalıdır.

Kentsel kamusal açık alanların tasarımları, iklim, bölge özellikleri, kentli ihtiyaçlarını karşılayacak şekilde, kentsel planlama dahlinde olmalıdır. İnsan hareketlerinin ve etkinliklerinin göz önünde bulundurulması, insanların kendilerini konforlu ve güvenli hissedecekleri alanlar yaratılması, kamusal açık alanlarla etkileşim kurulması açısından önem teşkil etmektedir. Mevcutta bulunan ayrık kent mekânlarının bir arada düşünülmesi kamusal kullanımları ve yaşam kalitesini olumlu etkileyecektir. Bunun yanında, özel mülkiyette bulunan ticari alanların kamusal açık alanlarla birlikteliğinin sağlanması, ticari sürekliliği oluştururken, kamusal yaşama katkı sağlayacaktır. Aynı zamanda özel mülkiyetteki yapıların dış mekân yaşantısının düşünülmesi, kamusal açık alanlar ve doğal çevre ile ilişkisinin sağlanması, yaşanabilir alanlar oluşturmak için gerekli görülmektedir.

Yeni tasarlanacak ve düzenlenecek alanlarda, kamusal alan olgusunda belirtilen kendini ifade edebilme, etkileşim içinde olma, kullanım, kullanıcı ve faaliyet ilişkisi göz önünde bulundurulmalıdır. Yerleşim bölgelerindeki kamusal açık alanların düzenlenmesi, hem bireylerin dış mekân yaşantısını sürdürmek için, hem de kentsel yapıların yoğunluğunun azaltılması için önem taşımaktadır. Yaşama alanlarının yürüme mesafesinde oluşturulması, farklı işlevlere ait kullanımların bir aradalığının sağlanması canlı kentsel alanlar oluşmasına katkı sağlayacak ve kamusal açık alanları zenginleştirecektir. Sağlıklı çevre yaratmak için, trafik yoğunluğunun düşürülmesi, özel taşıt kullanımındansa kontrollü toplu taşımaya ağırlık verilmesi, taşıt yaya birlikteliğinin sağlanması ve taşıtın yaya üzerindeki olumsuz etkisinin ortadan kaldırılması için yeşil koridorlarla tampon bölgeler oluşturulması önem arz etmektedir.

Sonuç olarak, tarihsel olarak bakıldığında, salgın süreçlerinin sonucunda, toplumsal ve siyasal değişikliklerin yaşandığı gerçeği göz önünde bulundurularak, kentsel kamusal açık alanlara yönelik geliştirilecek planlama ve bakım yönetiminin kamu ve özel kurumların iş birliği öncülüğünde ele alınması ve yeniden düzenin kurulması yönünde çalışmalar yapılması gerekmektedir. Salgın süreci, temiz hava, güneş ışığı ve yeşil alana ulaşacağımız kamusal açık alanların gerekliliğini ortaya çıkarmıştır. Kentlerde sosyal ve fiziksel mesafelendirmeye yönelik kentsel kamusal açık alan çözümleri ve kentli için yaşanabilir, yürünebilir sağlıklı bir yaşam kalitesi sunan planlar düzenlenmesi gerekliliği göz önünde bulundurularak, çalışmalara hız kazandırılmalıdır.

\section{Kaynaklar}

Arendt Hannah, Insanlık Durumu, Çev.: (B.S.Şener). İletişim Yayınları, İstanbul 2012.

T. Banerjee, "The Future of Public Space: Beyond Invented Streets and Reinvented Places", Journal of the American Planning Association, 67(1), 2001, s. 9-24.

Carmona, Matthew, Public Places - Urban Spaces, Routledge, London 2010.

Carmona, Matthew, Magalhães, Claudio de \& Hammond, Leo, Public Space The Management Dimension, Routledge, London and New York 2008.

Carr, Stephen , Francis, Mark, Rivlin, Leanne G., \& Stone, Andrew M, Public Space, Cambridge University Press, Cambridge 1992.

Fishman, Robert, Bourgeois Utopias, Readings in Urban Theory, Çev.: (S.Fainstein \& S.Campbell), Blackwell, Cambridge 1996, s. 23-60. 
Fishman, Robert, 20. Yüzyılda Kent Ütopyaları, 20. Yüzyıl Kenti Der.: (Duru, B., Alkan A.), İmge Kitabevi, Ankara 2002.

Gehl, Jan, Towards A Fine City For People - Public Spaces - Public Life. Transport for London and Central London Partnership, London 2004.

Gehl, Jan, Cities for People, Island Press, Washington 2010.

Girardet, Herbert, The Gaia Atlas of Cities, New Directions for Sustainable Urban Living, Gaia Books Limited, London 1996.

Habermas, Jürgen, Kamusallığın Yapısal Dönüşümü, Çev.: (T. Bora, M. Sancar), İletişim Yayınları, İstanbul 2000.

Holmes, Damian, How will our Cities Change After COVID-19?, 2020.

Howard, Ebenezer, Garden Cities of To-Morrow, MIT Press, Cambridge, 1965.

Hubbard, Phil, "Urban design and local economic development", Cities, 12(4), 1995, s. 43-251.

Jacobs, Jane, The Death and Life of Great American Cities, Random House, New York 1961.

Kalinski, John, The Present City and The Practice of City Design Çev.: (J.Chase \& M. Crawford), The Monacelli Press, New York 1999.

Louikatou-Sideris, Anastasia, "Cracks in the city: Addressing the constraints and potentials of urban design", Journal of Urban Design, 1(1), 1996.

Lynch, Kevin, Good City Form, MIT Press, Cambridge 1981.

Madanipour, Ali, Public and Private Spaces of the City, Routledge, London 2003.

Özdeş, G., "Şehir-Şehirlerin Fonksiyon Bölgeleri", Şehircilik, ITÜ Basım, İstanbul 1985.

Özer, B., "Doğumunun 100. Yılında Le Corbusier", Yapı Dergisi, 76, 1987, s. 27-53.

Punter, John V. "The Privatisation of Public Realm", Planning, Practice and Research, 5(3), 1990, s. 9-16.

Sadler, David, Place-marketing, competitive places and the construction of hegemony in Britain in the 1980s, In Selling Places: The City as Cultural Capital, Past and Present, Oxford, Pergamon Press, New York, Seoul, Tokyo 1993, s. 175-192.

Sadler, Simon, Archigram (1st Edition). MIT Press, 2005.

Sennett, Richard, Kamusal İnsanın Çöküşü, Çev.: (S.Durak, A. Yılmaz), İstanbul 2002.

Thompson, I. H., Landscape and Urban Design, Ed.: (M. Roberts \& C. Greed), Introducing Urban Design, Longman, Essex 1998, s. 105-115.

Whyte, William, The Social Life of Small Urban Spaces, PPS Project for Public Spaces Publication, Washington 1980.

URL-1 Welvyn Bahçe Kenti. Erişim Tarihi: Aralık 15, 2020, 14:10

https://en.wikipedia.org/wiki/Welwyn_Garden_City

URL-2 Unité d'Habitation. Erişim Tarihi: Aralık 10, 2020, 12:40 
https://tr.wikipedia.org/wiki/Unité_d\%27Habitation

URL-3 Chandigarh. Erişim Tarihi: Aralık 2, 2020, 10:37

http://www.lecorbusier.com/corbuweb/morpheus.aspx?sysName=redirect64\&sysLanguage=enen\&lrisObjectld=9192\&sysParentld=64

URL-4 Spatial City. Erişim Tarihi: Aralık 10, 2020, 18:24

http://www.yonafriedman.nl/?page_id=78

URL-5 Armada Alışveriş Merkezi. (2020). Erişim Tarihi: Kasım 10, 2020, 13:55

https://www.armadaavm.com.tr/hakkimizda

URL-6 Ankara kent merkezi ve çevresi yeni oluşumlar. Erişim Tarihi: Kasım 10, 2020, 17:34

https://tr.wikipedia.org/wiki/Dosya:Ankara_Kalesi\%27nden_şehir_panoraması.JPG

URL-7 Ankara kentsel parçalanma. Erişim Tarihi: Mayıs 15, 2019,13:32

https://muazergu.com/2019/06/29/ankaranin-pariltili-semti-cukurmabar/

URL-8 Milan. (2020). Erişim Tarihi: Temmuz 10, 2020, 15:22

https://www.bbc.com/news/world-europe-52483684

URL-9 Brooklyn, Domino Park. Erişim Tarihi: Mayıs 19, 2020, 17:23

https://www.designboom.com/design/domino-park-circles-glasssocialdistancing-05-19-2020/

URL-10 İstanbul - İzmir Parklar. (2020). Erişim Tarihi: Ağustos 30, 2020, 14:46

https://www.sozcu.com.tr/2020/gundem/istanbulda-cemberli-sosyal-mesafe-donemi-boyle-

goruntulendi 5836913/?utm_source=ilgili_haber\&utm_medium=free\&utm_campaign=ilgilihaber 